https://artnodes.uoc.edu

\title{
Reimaginar el tiempo de la condición póstuma. Una aproximación desde la activación del esquema «"¿y si...?”" "entonces"” en cuanto thought experiment
}

\author{
Marc Boqué \\ Universitat Oberta de Catalunya
}

Fecha de presentación: octubre de 2021

Fecha de aceptación: diciembre de 2021

Fecha de publicación: enero de 2022

\section{Cita recomendada}

Boqué, Marc. 2022. «Reimaginar el tiempo de la condición póstuma. Una aproximación desde la activación del esquema "¿y si...?" — "entonces"» en cuanto thought experiment». En: Garcés, Marina (coord.). «Ecología de la imaginación». Artnodes, no. 29. UOC. [Fecha de consulta: dd/mm/ aa]. https://doi.org/10.7238/artnodes.v0i29.393018

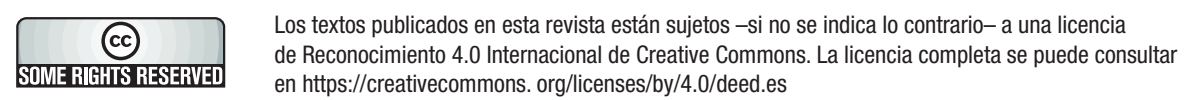

\section{Resumen}

En tiempos en los que el relato dominante se fundamenta en una alerta global permanente, nuestra imaginación entra en crisis. El «¿y si...?» amenazante la dirige hacia un «entonces» donde, por un lado, reside el apocalipsis y, por el otro, la tecnoutopía. En ambos casos, esta imaginación se proyecta hacia un futuro en el que los humanos dejamos de intervenir sobre nuestras condiciones de vida y, por tanto, queda alejada de cualquier tipo de experimentación con el presente. Pero ¿cómo desanclar esta imaginación de la necesidad que implica la evolución predecible de nuestra realidad actual? ¿Cómo desligarla de sus miedos, su devastación o su precariedad? 


\title{
artnodes
}

https://artnodes.uoc.edu

Reimaginar el tiempo de la condición póstuma. Una aproximación desde la activación del esquema "¿¿y si...?" — "entonces"» en cuanto thought experiment

En este artículo, investigamos la relación que guarda la imaginación con el experimento mental a partir del análisis de los ejemplos que nos proporcionan el aforismo 341 de La gaya ciencia de Nietzsche, el desarrollo de la teoría relatividad especial de Einstein y la película Memento de Christopher Nolan. Todos ellos se presentan bajo el triple sentido que Nietzsche dio al termino Versuch. Es decir, como ensayos, probaturas y tentativas que, en este caso, tendrán la función de reinterpretar la condición lineal y absoluta del tiempo. Los resultados de estos experimentos nos tendrán que servir en la última parte de nuestro trabajo para habilitar las condiciones que una imaginación colectiva debería tener actualmente para ser revulsiva ante el tiempo que proclama nuestra condición póstuma.

\section{Palabras clave}

imaginación; relatividad; tiempo; experimento mental

\author{
Reimagining the time of posthumous condition. An approach from the activation of the scheme \\ “'What if...?' - 'Then'” as thought experiment
}

\begin{abstract}
In times when the dominant narrative is based on permanent global alert, our imagination goes into crisis. The threatening "what if..." directs us towards a "then" where, on the one hand, there is the apocalypse and, on the other hand, there is the techno-utopia. In both cases, this imagination is projected onto a future in which humans stop intervening with our living conditions, and we are removed from any kind of experimentation with the present. But how can we separate this imagination from the necessity implied by the foreseeable evolution of our current reality? How can we disentangle it from its fears, its devastation or its precariousness?

In this research paper, we investigate the relationship between imagination and the thought experiment based on an analysis of the examples provided by Nietzche's aphorism 341 of The Gay Science, the development of Einstein's special relativity theory and the film Memento by Christopher Nolan. All these examples are presented under the triple meaning that Nietzsche gave to the term Versuch. That is, as trials, tests and attempts that, in this case, will serve to reinterpret the linear and absolute nature of time. The results of these thought experiments will help us, in the final part of our work, to find the conditions that a collective imagination needs in order to be revulsive before the time proclaimed by our posthumous condition.
\end{abstract}

\section{Keywords}

imagination; relativity; time; mental experiment 


\section{artnodes}

https://artnodes.uoc.edu

\section{Introducción}

Es cierto, como constataba hace ya unos años Marina Garcés, que vivimos bajo un imaginario colectivo que otorga a nuestro tiempo una condición póstuma (Garcés 2019, 13-21). Que el tiempo se nos acaba, que el mundo que habitamos se dirige hacia su final por colapso nuclear, ambiental, pandémico..., ha pasado a configurar en nuestros días lo que Josefina Ludmer, hace apenas una década y con esperanza, definía como nuestra «imaginación pública». Literatura, películas, series, alegatos políticos y ecologistas, en definitiva: «todo lo que circula en forma de imágenes y discurso; [esa] red que tejemos y que nos envuelve, nos penetra y nos constituye» (Ludmer 2012), deviene hoy una fábrica de realidad invadida por el relato posapocalíptico o, en el otro extremo, por un neofuturismo virtual que termina diluyendo lo propiamente humano a un twist finger. Esta condición póstuma, que según Garcés es el después de una muerte que no es nuestra muerte real, sino una muerte histórica producida por el relato dominante de nuestro tiempo, ha logrado superar nuestra anterior condición posmoderna. En esta transición, hemos pasado a substituir el presente eterno que proclamaba la posmodernidad por el tiempo del no futuro, a voltear las biopolíticas afirmativas y preservadoras de la vida por un necrocapitalismo cuya condición es la muerte y, finalmente, a invertir la incredulidad del pensamiento contemporáneo en los grandes relatos hacia un nuevo relato lineal y único que nos lleva a la extinción (Garcés 2016). Y es constatable, si echamos una ojeada a las predicciones que se hacen desde los más diversos campos, que nuestra cultura actual tiende a conjeturar el final de una historia en el que dejamos de intervenir sobre nuestras condiciones de vida. Ahora, en efecto, ya desprovistos de esas utopías modernas basadas en una idea de progreso que nos tenía que lanzar hacia un futuro prometedor, pero también más allá de ese presente eterno que nos prometía la posmodernidad, parecemos abocados a recorrer un tiempo de prórroga que nos lleva hacia nuestra propia nada. Es ante esta conciencia derrotista que se acrecientan los miedos de los que hacía inventario Z. Bauman en su obra Miedo líquido (Bauman 2006). Temores coherentes con nuestra ignorancia sobre la amenaza concreta que se cierne sobre nosotros y que somos incapaces de replicar. Miedo a seguir creciendo económicamente y devorando los recursos del planeta. Miedo a la autodestrucción. Miedo a un virus conocido o por conocer, pero también a vacunas asesinas. Miedo incluso al prójimo, que mantenemos fuera de nuestras fronteras comunitarias 0 personales erigidas sobre un firme paradigma de la inmunidad.

Uno de los problemas que presenta este miedo difuso y siempre asociado al fin del tiempo humano es que constituye una fuerza limitadora para la acción imaginativa. Y es que esta última, desplegada a partir de una «alerta global» permanente, se cimienta hoy sobre un «iy si...?» que tiende a resolverse en un «entonces» que solo admite como respuesta la necesidad de una alternativa. Efectivamente: « $i Y s i$ no somos capaces de revertir el cambio climático?», « ¿y si algún país inicia una guerra nuclear?», «iy si se termina el petróleo?», « ¿y si hay
Reimaginar el tiempo de la condición póstuma. Una aproximación desde la activación del esquema «"¿y si...?" - "entonces"» en cuanto thought experiment

un apagón total de la red virtual 0 eléctrica?» 0 « ¿y si surge una mutación de la COVID-19 todavía más mortal?» son alertas que proyectan nuestra imaginación hacia un futuro, a la par previsible y fantasioso, en el que podemos sobrevivir o no, pero que, en cualquier caso, truncan cualquier forma de experimentación con el presente.

Pero ¿cómo transfigurar ese «¿y si...?» que solo admite la violencia de la contradicción como respuesta? ¿Cómo decodificarlo de esta necesidad de la alternativa para que emerja un «entonces» que active la contingencia en la imaginación? En este artículo, ensayamos una posible activación de esta estructura " ¿y si...?" - "entonces"» a partir del análisis de tres ejemplos en los que se pone en práctica lo que denominaremos un thought experiment desde un punto de vista filosófico-literario, científico y cinematográfico. Tienen todos ellos la característica común de que abordan una reinterpretación del concepto de tiempo que, defenderemos, permite poner en juego una imaginación que devendrá revulsiva frente a la que la condición póstuma agracia.

\section{Nietzsche: del aforismo como Versuch al tiempo del eterno retorno}

Sería aventurado declarar que prevalece una teoría unitaria de la imaginación a lo largo de toda la obra de Nietzsche y, sin embargo, esta facultad parece alentar el desarrollo de una de las formas literarias más habituales que el de Röcken utilizará para exponer sus pensamientos a partir de Humano, demasiado humano. En efecto, el aforismo aparecerá por primera vez en esta obra confeccionado para estimular el nuevo modo de hacer y vivir la filosofía en el camino de la autoexploración que Nietzsche practicará desde 1878 , y, de esta manera, para romper con toda voluntad sistemática y abrirse a una zona fragmentaria «donde la unidad discursiva no se presupone, $y$ el pensamiento debe aclimatarse a un espacio de verso libre» (Morey 2018, 195-196). Esta zona poética, que nosotros relacionaremos con la imaginación en la primera parte de nuestro artículo, quedará regida, según destaca Manuel Barrios, por el triple sentido que Nietzsche otorgó al término Versuch. En primer lugar, como ensayo 0 intento de aproximarse a un problema por la vía del tanteo y sin voluntad de cierre definitivo. En segundo lugar, en cuanto probatura con la verdad. Finalmente, como una tentación o conato de seducción, es decir, como una manera de apropiarse del instrumental del pensamiento para atraerlo a una nueva tarea crítica (Barrios 2019). Tres sentidos que, juntos, conformarán el carácter de experimento mental que W. Kaufmann destacó por primera vez en el aforismo:

Cada aforismo o secuencia de aforismos [...] puede considerarse como un experimento mental [...] Nietzsche insiste en que el filósofo debe estar dispuesto a hacer experimentos nuevos; debe mantener una mente abierta y estar preparado, si es necesario, para declararse en todo momento sin temor en contra de su anterior opinión, igual como se esperaría de un científico que revisara sus teorías a la luz de Ios nuevos experimentos (Kaufmann 1968, 85-86). 


\section{artnodes}

https://artnodes.uoc.edu

Un ejemplo donde se pone de manifiesto toda la fuerza del aforismo en cuanto Versuch lo constituye el conocido aforismo 341 de La gaya ciencia, titulado «El peso más pesado». Nietzsche sacará a relucirla ubicándonos en una situación imaginaria a partir de una pregunta que terminaremos por descubrir que no admitirá más respuesta que la que cada uno de nosotros seamos capaces de brindar a través de nuestra propia experiencia vital. En este sentido, podemos abordar la estructura del aforismo a partir de un esquema similar al que utilizábamos para poner de relieve la alerta global y la respuesta en la que nos situaba la condición póstuma. Una esquematización consistente en substituir la pregunta que abre el aforismo: «¿Qué te sucedería si un día o una noche se introdujera furtivamente un demonio en tu más solitaria soledad y te dijera: "Esta vida, así como la vives ahora y la has vivido, tendrás que vivirla [...] innumerables veces más..." por un "¿y si...?" que dirigiría directamente al lector hacia un "entonces" que este tendría que completar mediante una respuesta: “№ te arrojarías al suelo y rechinarías los dientes...? / ¿0 has vivido alguna vez un instante tremendo en el que responderías ' $\mathrm{i} E r e s$ un dios y nunca escuché nada más divino!'”»? (Nietzsche 1985, FW, 341).

Las repercusiones que este esquema tiene para el desarrollo de la imaginación en ambos casos son evidentes. Pero ¿qué diferencias presenta esta estructura "¿iy si...?" — "entonces"» en cada una de las situaciones? Para empezar, tenemos que observar que en ambas se nos sumerge en una situación ficticia que reclama una solución, pero una solución que rápidamente comprobaremos que diferirá radicalmente en cada caso. Así, mientras que el «iy si...?» que nos propone el relato póstumo nos proyecta hacia un futuro que, como hemos visto, se resuelve a partir de una respuesta contradictoria (sobrevivimos/no sobrevivimos), pero de la que nada sabemos y por tanto solo podemos predecir, el «y si» que nos plantea el aforismo nietzscheano nos aboca a «un hueco» que tendrá que ser rellenado a partir del propio diagnóstico vital establecido en el presente. Un diagnóstico vital, no obstante, que al contrario de lo que podría parecer a primeras no nos invitará al cómputo 0 al balance. Es decir, a poner en una balanza los pros y los contras para concluir finalmente si ha valido la pena vivir la vida como la hemos vivido o no, sino más bien a fijarnos y pensar en esos «instantes tremendos»

... en los que más allá del pasado y del futuro, la vida en su presente es puesta como absoluta e incondicionalmente valiosa: instantes en los que, para poder detenerlos, uno aceptaría incluso la repetición de la vida entera y todo su pasar anterior, porque son precisamente los que ahora la redimen y más allá de cualquier posible cálculo (Morey 2018, 265).

A lo que nos tienta Nietzsche con este aforismo es, pues, a poner en cuestión ese futuro que no nos puede ofrecer más que las dinámicas que actualmente nos alienan. ¿Cómo? Desencadenándolo de la necesidad que
Reimaginar el tiempo de la condición póstuma. Una aproximación desde la activación del esquema "¿¿y si...?" — "entonces"» en cuanto thought experiment

implica la evolución previsible de nuestra realidad presente -esa que no firmaríamos jamás repetir innumerables veces- para encadenarlo a las posibilidades que ese mismo presente nos puede ofrecer a través de sus instantes. Un presente que, en este caso, ya no podrá darnos más respuestas que las que cada uno pueda hallar a través de su propia vivencia.

Es mediante esta absolutización de la vida que Nietzsche desplaza el umbral que la imaginación de la condición póstuma colocaba al final de los tiempos a un instante cualquiera. Una imaginación que, asentándose en ese «sí» a la vida, se plantea qué pasaría si no existiese un mañana y que por ello también deviene crítica y exigente. ¿Qué es lo que ha valido la pena vivir de lo que hasta ahora he vivido? Pero también: ¿qué podría cambiar? Una imaginación, en definitiva, que es la tentación de un ejercicio cognoscitivo mediante el cual se nos emplaza a aprender algo acerca de nuestra propia experiencia de la vida y a hacerlo por medio del pensamiento (Morey 2018, 262).

\section{La imaginación y la teoría del tiempo relativo}

El «"¿y si...?" - "entonces"» que estructura el aforismo 341 de La gaya ciencia promueve un tipo de imaginación capaz de transfigurar el tiempo lineal y necesario que rige la condición póstuma y su carácter teleológico. En este aspecto, se ha querido destacar la fuerza ética que este experimento narrativo conlleva a la hora de afirmar la vida («obra de tal suerte que quieras también la eterna repetición de lo que quieres»). Ahora bien, ¿una práctica cognoscitiva del tipo practicado por el versucher también es apta para sostener científicamente la teoría alternativa del tiempo que nos propone el eterno retorno («todo vuelve»)?

Generalmente, las dudas ante esta pregunta nos surgen porque históricamente hemos tenido tendencia a vincular la imaginación con el relato ficticio, aunque mucho menos con una facultad individual 0 colectiva competente para fundamentar una teoría científica. En este aspecto, la teoría de la relatividad especial de Einstein, en la que profundizamos en esta segunda parte de nuestro artículo, supone un excelente ejemplo para percatarnos de la potencia que este " $¿ y$ si...?" - "entonces"» puede presentar a la hora de transformar la propia concepción de la realidad. Para empezar, podemos afirmar que Einstein encajaba a la perfección con esa definición que Nietzsche daría del filósofo del futuro como versucher (Nietzsche 2012, JGB, 42). Y encajaba porque el arma que el autor de la teoría de la relatividad compartió durante toda su vida con esos espíritus libres, efectivamente, fue la de tentar la realidad por medio de experimentos de pensamiento. Un thought experiment cuyos fundamentos tenemos que ir a buscar, según las propias palabras de Einstein, en las influencias epistemológicas que recibió de E. Mach y D. Hume. ${ }^{1}$ Del primero,

1. El termino Gedankenexperiment sería utilizado por primera vez en 1812 por el físico y químico danés Hans Christian Orsted como sinónimo de Gedankenversuch. La traducción al inglés de thought experiment la encontramos a partir de 1897, precisamente, a raíz de la traducción de un ensayo de E. Mach. 


\section{artnodes}

https://artnodes.uoc.edu

Einstein destacaría que tuvo el gran mérito de entrever que los grandes problemas físicos, antes que ser de naturaleza deductivo-matemática, estaban fundamentados sobre principios básicos que, sin embargo, la tradición científica no había puesto jamás en duda. Una influencia esta que fomentaría en Einstein la necesidad epistemológica de poner bajo sospecha estos principios con el fin de justificarlos empíricamente 0 , en el caso de que fuera imposible, eliminarlos para substituirlos por otros que sí cumplieran esas condiciones empíricas (Einstein 1998, 227). De Hume, del cual el propio Einstein llegaría a declarar que había leído «con avidez y admiración» su Tratado sobre la naturaleza humana «poco antes de descubrir su teoría de la relatividad» (Einstein 1998, 220), podemos destacar que aprendería a hacer uso de las dos facultades que para el escocés fundamentaban el conocimiento: la memoria y la imaginación. La memoria, como es sabido, tendrá para Hume, en primer lugar, la función de hacer revivir en forma de ideas las impresiones pasadas, pero, en segundo lugar, también la de preservar su orden y su posición. Por su parte, la imaginación será la facultad que para Hume tendrá la libertad para combinar estas ideas de forma espontánea 0 natural mediante las leyes de asociación (semejanza, contigüidad en el tiempo y lugar, causa y efecto), con el fin de alterar su orden (Hume 2005, 52-54).

Pensar para Hume constituye un ejercicio que se desarrolla a caballo entre la memoria y la imaginación. Un pensar que, por esta razón, será capaz de suponer ideas que irán más allá de los límites ordenadores a los que la memoria lo someterá, pero que tendrá su justificación en el grado de comprensión que con su ayuda podremos adquirir sobre las experiencias de los sentidos. Por ello podrá afirmar:

Fijemos nuestra atención sobre nosotros mismos tanto como nos sea posible; dejemos caminar nuestra imaginación hasta los cielos o hasta Ios últimos límites del universo: jamás daremos un paso más allá de nosotros mismos ni jamás concebiremos un género de existencia más que estas percepciones que han aparecido en esta estrecha esfera. Este es el universo de la imaginación y no poseemos más ideas que las que allí se han producido (Hume 2005, 125).

Los imperativos que Mach y Hume conceden a este quehacer científico se pueden rastrear tras el florecimiento de la teoría de la relatividad especial de Einstein. De hecho, si partimos de estos, podemos hacer una lectura de esta teoría en clave de experimento mental. Efectivamente, visto epistemológicamente, el principal mérito que hallamos tras los artículos que el joven Einstein publicaría en 1905 tendrá que ver con la articulación de una sospecha en torno a un concepto de tiempo absoluto que no habría pasado el filtro de la experiencia. Esta sospecha surgiría a partir de un problema físico en boga a principios del siglo xx: la supuesta incompatibilidad entre el principio de relatividad de Galileo-Newton y la ley de propagación de la luz en el vacío. Resumiremos rápidamente que el principio de relatividad dicta que es imposible diseñar experimento alguno que dilucide si uno está en
Reimaginar el tiempo de la condición póstuma. Una aproximación desde la activación del esquema "¿¿y si...?" — "entonces"» en cuanto thought experiment

reposo o en movimiento rectilíneo uniforme. Y lo es porque en ambos sistemas de referencia (reposo y M. R. U.) los fenómenos naturales seguirán las mismas leyes. Por su parte, la ley de propagación de la luz en el vacío establece que esta se mueve en línea recta y a una velocidad constante de $300.000 \mathrm{~km} / \mathrm{s}$. Ahora, la incompatibilidad entre este principio y esta ley la podemos sintetizar de la siguiente manera: si aceptamos todas las consecuencias del principio de relatividad, tendremos que admitir que no hay un sistema inercial privilegiado sobre el resto para fundamentar nuestros cálculos, cosa que hará que estos difieran dependiendo del sistema a partir del cual sean tomados. Pero, siendo así, ¿cómo es posible que en todos los sistemas de referencia funcione una ley que dice que la velocidad de la luz es siempre la misma? ¿No tendría que ser esta velocidad también relativa al sistema de referencia desde el cual se la tome?

Ante este dilema, a principios del siglo xx parecía inevitable renunciar 0 bien al principio de relatividad o bien a la ley de propagación de la luz. Más teniendo en cuenta que las revolucionarias investigaciones teóricas de H. A. Lorenz sobre los procesos ópticos y electromagnéticos de la época habían mostrado que las experiencias en este dominio conducían necesariamente a una teoría de los procesos electromagnéticos que tenía como consecuencia inexcusable la ley de constancia de la velocidad en el vacío. ¿Se tenía, pues, que desechar el principio de relatividad que había fundamentado buena parte de la física clásica, aunque no se hubiese encontrado ningún hecho experimental que lo contradijese? (Einstein 2000, 16).

El thought experiment de Einstein empieza en este punto crítico y su desarrollo lógico es arrolladoramente simple. Einstein, tomando como imperativos el principio de sospecha y una imaginación cuyo límite tendrá que abrigar la experiencia, partirá de que tanto el principio de relatividad como el de propagación de la luz han sido principios probados por la percepción empírica, y que, por tanto, pueden ser asumidos como los dos postulados o premisas de un silogismo a partir del cual extraer conclusiones. No habrá ninguna dificultad en deducirlas siempre que estemos dispuestos a abandonar la idea de que el tiempo es absoluto. De hecho, este es el único concepto de la triada que hasta el momento no ha sido probado por la experiencia empírica. ${ }^{2}$

La sospecha de Einstein se articula a través de un «¿y si...?» que apunta a la validez de un concepto de simultaneidad del tiempo que hasta el momento solo el sentido común había sido capaz de sostener, y se responde a través de un «entonces» que abre las puertas de una nueva teoría del espacio-tiempo. A partir de ese momento todos los espectadores tomaremos la misma velocidad de la luz, aunque todos tendremos nuestra medida del espacio y el tiempo relativas. Es decir, el principio de relatividad de Newton y la ley de propagación de la luz en el vacío serán compatibles a costa de que cada uno de nosotros lleve un reloj propio cuyas agujas avanzarán según el ritmo en que nos

2. Para el desarrollo de los cálculos, cfr. Boqué (2016, 69-73). 


\section{artnodes}

https://artnodes.uoc.edu

movamos (teoría de la relatividad) 0 , más tarde, según la gravedad a la que seamos sometidos (teoría de la relatividad general). El tiempo, en definitiva, como consecuencia de este experimento mental, será algo que llevamos cada uno de un lugar a otro y que ya no podrá ser independiente de nuestra experiencia particular.

\section{Ensayos cinematográficos y condiciones para revocar la imaginación póstuma}

Los thought experiments de Nietzsche y Einstein permiten abrir nuevas concepciones del tiempo que lidian con la del tiempo del «todo se acaba». Son concepciones que rompen con la necesidad y que permiten desarrollar una imaginación que se abre a la posibilidad que nos brinda una experiencia a la vez vivencial y crítica. De hecho, si miramos hacia el ámbito de la ciencia ficción, estas nuevas concepciones del tiempo han permitido en los últimos años desarrollar una serie de películas que han trastocado el ámbito apocalíptico, pero, aún más, han puesto límites a la propia ficción entendida como fantasía. Un director que hay que tener en cuenta en este sentido es Christopher Nolan, que ha declarado en más de una ocasión que los principios científicos han sido para sus guiones mucho más exóticos y asombrosos que cualquier propuesta que hubiese salido de su imaginación. Esta connivencia entre ciencia e imaginación la podemos constatar a través del ejemplo que nos proporcionan sus películas, cuyos argumentos tienen como fulcro el enigma del tiempo. Destacable en este aspecto es Interestellar (Nolan 2014), en cuya narración hay implicados algunos principios de la relatividad general anteriormente expuestos, aunque en este caso nos interese poner de relieve el experimento mental que realiza Nolan en Memento (2000). En esta película el director nos traslada al mundo de la amnesia anterógrada que sufre Leonard Shelby a partir de un traumatismo craneoencefálico que sufrió en el pasado, y de las dificultades que tendrá a partir de ese momento para almacenar recuerdos más allá de unos minutos. Lo destacable es que estas dificultades serán trasladadas a la línea temporal de la película que, desarrollada mediante constantes analepsis y prolepsis creadas a partir de las fotos y tatuajes que Leonard creará para tener un registro de los elementos básicos para el desarrollo de su vida, también nos permitirá ser partícipes como espectadores del problema central planteado: la inextricable relación que mantienen el tiempo y la memoria. «¿Cómo se supone que me voy a curar si no soy capaz de sentir el paso del tiempo?», dice en algún momento el protagonista de la película. Es decir, nada sucede si no lo recordamos. Y si Leonard no puede recordar, nosotros, los espectadores, tampoco.

Los ejercicios cinematográficos de Nolan, al lado de los ético-literarios practicados por Nietzsche en sus aforismos o los lógico-deductivos de Einstein a la hora de elaborar sus teorías científicas, constituyen ensayos, probaturas, tentativas sobre el tiempo. Prácticas que, en consecuencia, también nos permiten entrever las condiciones bajo las
Reimaginar el tiempo de la condición póstuma. Una aproximación desde la activación del esquema "“¿y si...?" - "entonces"» en cuanto thought experiment

que debería operar una imaginación reactiva al tiempo de la condición póstuma. Pensamos, como mínimo, en cinco:

1) Condición de actualidad: contra una imaginación destinada a la predicción del futuro, utópico o distópico, la imaginación en concomitancia con estos experimentos mentales nos aboca al presente;

2) Condición de posibilidad: abocarse al presente, sin embargo, no significa en ninguno de los ejemplos analizados hacer de este presente un programa generador de futuro. En este caso seguiríamos hablando de necesidad. Sino más bien de abrirlo a una dimensión de la contingencia que nos libera precisamente de las formas implícitas del presente;

3) Condición de experiencia: una imaginación abierta al devenir del presente significa que ha de generar posibilidades a través de la experiencia propia o compartida y no de la reproducción de patrones 0 , en el otro extremo, de la fantasía. Por tanto, una imaginación experiencial preferimos decir que ensaya más que crea;

4) Condición de sospecha: por las cuatro condiciones anteriormente expuestas, la imaginación vinculada a todos los thought experiments presentados, en algún aspecto, pone en cuestión la racionalidad corriente 0 el sentido común.

Estas condiciones de posibilidad para revocar la imaginación ligada a la condición póstuma, no obstante, pensamos que quedarían desvirtuadas sin una quinta condición que podemos denominar de limitación de la velocidad experiencial. La razón es que sin la restricción que impone esta condición bien se podría pensar que el resto de condiciones ya han sido actualmente cristalizadas en la imaginación colectiva que implícitamente acoge la red virtual. De hecho, más allá del apocalipsis que proclama nuestro tiempo, desde los años noventa del siglo pasado la red ha constituido un flujo de desembocadura para muchas de las tecnoutopías. Incluso hasta el punto de que muchas voces quisieron vincular este conjunto descentralizado de redes de comunicaciones interconectadas que es internet a los lenguajes rizomáticos del posestructuralismo. No nos parece que fueran desencaminadas: la red funciona a través de un sistema conectivo de nodos intercambiables que bien podemos asociar con el sistema semiótico conjuntivo $(\mathrm{y}-\mathrm{y})$ del que nos hablaban G. Deleuze y F. Guattari en la introducción de Mil mesetas (Deleuze y Guattari 2004, 9-29). Una red virtual rizomática que nunca procedería mediante la alternativa o la exclusión (0-0), sino a partir de una serie de alteraciones, proliferaciones y recomposiciones que permitían una esfera de planos múltiples (Berardi 2015, 134-135). Internet, en otras palabras, sería una red en la que la relación no se establecería nunca por rutas dadas por adelantado, sino mediante una proliferación de rutas posibilitadas en cada momento por el intercambio de sus nodos o participantes. Una estructura en la que, sin demasiadas dificultades, podríamos insertar las condiciones de actualidad, contingencia, ensayo y sospecha que considerábamos indispensables para desarrollar la imaginación.

¿Dónde reside entonces el problema? Pues que internet, en cuanto red conectiva, se desarrolla en una dimensión espacial infinita, pero en la 


\section{artnodes}

https://artnodes.uoc.edu

que nos movemos bajo la dimensión de un tiempo de experiencia finito Efectivamente, en primer lugar, internet es un ciberespacio constituido por la interacción de innumerables fuentes humanas y mecánicas de enunciación que se expande ilimitadamente. Pero, en segundo lugar, también una red de conexiones que se establece a través de un cibertiempo que no se puede expandir ilimitadamente «porque está vinculado a la intensidad de la experiencia que el organismo consciente dedica a elaborar informaciones que provienen del ciberespacio" (Berardi 2015, 127). La disyuntiva, en síntesis, reside en que la cantidad de información que circula entre los distintos puntos de la red siempre es superior a la cantidad de información que como individuos podemos elaborar conscientemente. Por esta razón, podemos decir que internet provoca un fallo en nuestra capacidad de retención, pero no, como en el caso del personaje de la película de Memento, por una inoperancia de la memoria, sino por una saturación de esta. Las consecuencias de esta saturación se pueden constatar actualmente en muchos ámbitos, pero especialmente en el del conocimiento. Nuestra memoria colmada se substituye por dispositivos electrónicos de almacenamiento, pero este almacenaje ya no cumple el requisito indispensable que encontramos en la definición de experiencia. Es decir, rara vez supone un conocimiento que se ha adquirido al haberlo realizado, vivido, sentido o sufrido una o más veces.

La pregunta a partir de aquí es: ¿Cómo podemos seguir circulando por internet sobrellevando esta saturación? Pues considerando que internet actualmente quizás es más parecida a la red swarm de la que hablaba K. Kelly en los años noventa (1995) que a la rizomática que hoy en día aún defienden autores como P. Levy (1994). Es decir, una red entendida como un sistema de «mecanismos lógicos y técnicos que hacen posible una automatización de comportamientos gracias a la exterioridad técnica y simbólica» (Berardi 2014, 144). Bajo este principio de funcionamiento el internauta ya no sería el participante libre y capaz de tomar decisiones conscientes, sino una especie de abeja en un enjambre atado a una interconexión cada vez más densa de automatismos que reducirían su capacidad de decisión. Su conciencia, en este caso, solo sería relevante para hacer posible la reactividad, mientras que su sensibilidad tendería a desactivarse. Este enjambre digital, pensado en sus consecuencias emocionales por B-C. Han constituiría un nuevo tipo de masa social que carecería de un «nosotros» capaz de andar en una dirección 0 emprender una acción política común (Han 2014).

Esta saturación del tiempo experiencial, con su consecuente automatización de comportamientos, repercute en el desarrollo de la memoria y pone en entredicho la propia capacidad de reimaginar colectivamente nuestro tiempo. En este aspecto es importante poner de relieve esa condición que limita nuestra velocidad experiencial a la que hacíamos referencia anteriormente. La alta velocidad, de hecho, fue uno de los pilares fundamentales en los que se asentó el modo de productividad fordista y ahora también uno de los fundamentos indispensables para la creación de esos patrones de conducta, simples o complejos, que ejecutamos al navegar por internet y que requieren un mínimo de recursos atencionales. Pero la velocidad es la relación que físicamente
Reimaginar el tiempo de la condición póstuma. Una aproximación desde la activación del esquema "¿¿y si...?" — "entonces"» en cuanto thought experiment

se establece entre el tiempo y el espacio, y si queremos modificarla, al menos en nuestro caso, solo podemos hacerlo a partir de una de sus dimensiones. La razón ya ha sido apuntada: nuestra experiencia requiere de un tiempo de elaboración cuyo ritmo es infranqueable. Entonces para modificar la velocidad solo podemos acotar el espacio. Esto significa limitarlo a una red de interacciones que permitan a la memoria disponer del tiempo suficiente para elaborar objetos mentales en perspectiva, su relación, sucesión, potencialidad, pero también que permitan a la imaginación reordenarlos, interrogarlos y transformarlos. Pensamos que únicamente el reajuste entre estas dos dimensiones podrá establecer la velocidad adecuada que nos permita seguir encarando las tentaciones que genios y demonios nos han planteado a lo largo de la historia del pensamiento 0 , mejor, planteárnoslas a nosotros mismos. Por ejemplo, la siguiente: ¿Y si la pregunta que nos planteaba el demonio de Nietzsche en la más absoluta de nuestras soledades la planteara a un «nosotros»? ¿Y si un día o una noche se introdujera furtivamente y nos retara con un: «Esta vida, así como la habéis vivido y la vivís como humanos la tendréis que repetir innumerables veces más»? La respuesta parecería obvia: ¿Quién repetiría la estupidez, las fatigas, las carencias y la maldad que han presidido la vida de la humanidad? Pero recordemos que Nietzsche no nos invita a los cómputos ni a los juicios finales, sino a que pensemos juntos en esos instantes en los que hemos compartido experiencias (vividas, sentidas o sufridas) en las que hubiésemos querido firmar el pacto. Quizás en estos momentos valga la pena volver a asentar nuestra imaginación colectiva.

\section{Referencias bibliográficas}

Barrios Casares, Manuel. Tentativas de seducción. Madrid: Abada Editores, 2019.

Bauman, Zygmunt. Miedo líquido. Barcelona: Paidós, 2006.

Berardi, Franco. Después del futuro. Desde el futuro al cyberpunk. El agotamiento de la modernidad. Madrid: Enclave de Libros, 2014.

Boqué, Marc. «¿Quién hizo imaginar a Einstein destellos de luz en las ventanas de los trenes vistos desde los andenes?.» Thémata. Revista de filosofía 53, (enero-junio 2016): 63-86. D0l: https://doi. org/10.12795/themata.2016.i53.03.

Deleuze, Gilles y Guattari, Félix. Mil mesetas. Valencia: Pre-textos, 2004.

Einstein, Albert. The Collected Papers of Albert Einstein, vol. 8 (The Berlin Years: Correspondence, 1914-1917). Princeton: University Press. Robert Schulmann, A. J. Kox, Michel Janssen y József Illy, eds., 1999.

Einstein, Albert. La teoría de la relativitat $i$ altres textos. Barcelona: Pórtic, 2000.

Garcés, Marina. Nueva ilustración radical. Barcelona: Anagrama, 2019. DOI: https://doi.org/10.1387/pceic.20501.

Garcés, Marina. Inacabar el mundo. Conferencia en el CCCB https:// www.cccb.org/es/multimedia/videos/marina-garces/223347, 2016. (Barcelona, 29 de febrero). 


\title{
artnodes
}

https://artnodes.uoc.edu

Han, Byung-Chul. En el enjambre. Barcelona: Herder, 2014. DOl: https:// doi.org/10.2307/j.ctvt9k4gh

Hume, David. Tratado de la naturaleza humana. Madrid: Tecnos, 2005.

Kaufmann, Walter. Nietzsche, Philosopher, Psychologist, Antichrist. New Jersey: Princeton University Press, 1968.

Kelly, Kevin. Out of the control: The new biology of Machines, Social Systems, and The Economic World. New York: Basic Books, 1995.

Levy, Pierre. L'intelligencie collective. Pour une anthropologie du cyberespace. Paris: La Découverte, 1994.

Ludmer, Josefina. Lo que viene después. Texto de la intervención de Josefina Ludmer en el seminario-encuentro Literatura y después. Reflexiones sobre el futuro de la literatura después del libro incluido
Reimaginar el tiempo de la condición póstuma. Una aproximación desde la activación del esquema "“¿y si...?" - "entonces"» en cuanto thought experiment

dentro del programa de UNIA arte y pensamiento. 2012. (Sevilla, 17-19 abril).

Morey, Miguel. Vidas de Nietzsche. Madrid: Alianza, 2018.

Nietzsche, Friedrich. La voluntad de poder. Madrid: Edaf, 1985.

Nietzsche, Friedrich. La ciencia jovial. Caracas: Monte Ávila Editores, 1985.

Nietzsche, Friedrich. Más allá del bien y del mal. Madrid: Alianza, 2012.

Nolan, Christopher (director). Memento [Película]. Newmarket Films, Team Todd. 2000.

Nolan, Christopher (director). Interestellar [Película]. Legendary Pictures, Syncopy Films, Lynda Obst Productions. 2014.

\section{CV}

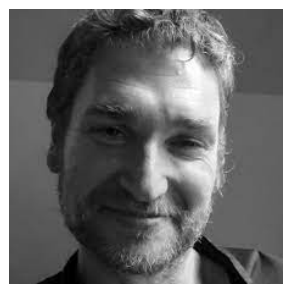

\author{
Marc Boqué \\ Universitat Oberta de Catalunya \\ mboquep@uoc.edu
}

Marc Boqué es licenciado en Filosofía por la Universidad de Barcelona y doctor en Filosofía por la Universidad de Zaragoza. A la vez, ha cursado estudios de los grados de Física y Economía en la UNED. Desde el año 2013 es profesor colaborador en el Área de Artes y Humanidades de la UOC, donde imparte las asignaturas de Pensamiento filosófico y científico moderno y Pensamiento filosófico y científico contemporáneo tanto en el grado de Humanidades como en el de Antropología y Evolución Humana. Actualmente, también es profesor del máster universitario de Filosofía para los Retos Contemporáneos impartido por esta institución y miembro del grupo de investigación MUSSOL. Compaginando intereses tanto en el ámbito de la filosofía como en el de la ciencia, sus trabajos de investigación versan sobre autores modernos y contemporáneos en los que se aúnan ambas disciplinas, poniendo especial atención a las problemáticas actuales que estas relaciones puedan abrir.

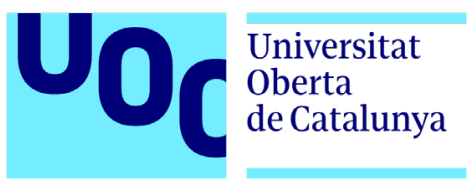

